\title{
Comparação das Contagens das Células de Langerhans de Tecidos Contendo Carcinoma Anal em Doentes com e sem Infecção pelo HIV
}

\section{Comparison of Langerhans Cells Counts from Tissues Containing Anal Carcinoma of Patients With and Without HIV Infection}

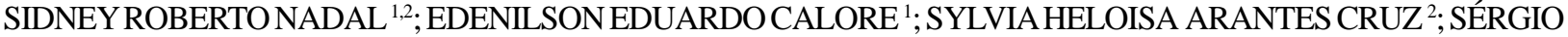 \\ HENRIQUE COUTO HORTA ${ }^{1}$; CARMEN RUTH MANZIONE ${ }^{1}$; FANG CHIABIN ${ }^{2}$; PERETZCAPELHUCHNIK ${ }^{2}$; \\ WILMARARTUR KLUG ${ }^{2}$
}

1. Médico do Instituto de Infectologia Emílio Ribas. 2. Médico da Disciplina de Coloproctologia do Departamento de Cirurgia da Faculdade de Ciências Médicas da Santa Casa de São Paulo. Brasil.

NADAL SR; CALORE EE; CRUZ SHA; HORTA SHC; MANZIONE CR; BIN FC; CAPELHUCHNIK P; KLUG WA. Comparação das Contagens das Células de Langerhans de Tecidos Contendo Carcinoma Anal em Doentes com e sem Infecção pelo HIV Rev bras Coloproct, 2006;26(3): 269-274.

RESUMO: INTRODUÇÃO: As células de Langerhans (LC) são derivadas da medula óssea e constituem-se nas principais apresentadoras de antígeno da pele.conferindo desta forma, a resposta imune cutânea. Seu número está reduzido nos imunodeprimidos, incluindo na infecção pelo HIV, e a presença do tumor inibe sua migração, impedindo que os linfócitos T promovam regressão das células neoplásicas. OBJETIVO: Conhecer as diferenças entre as contagens de LC no tecido tumoral de doentes de carcinomas anais com e sem AIDS. MÉTODO: Avaliamos 24 doentes, sendo 14 com HIV e 10 outros sem HIV . O tratamento para o carcinoma foi semelhante nos dois grupos. Cortes retirados de blocos parafinados submetidos ao teste imunoistoquímico com anticorpo anti-CD68. Contamos as LC com método da histometria e os comparamos aos números obtidos com amostras previamente conhecidas de doentes sem doença infecciosa anorretal ou infecção pelo HIV. Revisamos também a evolução e as contagens séricas de linfócitos T CD4+ de doentes HIV-positivos. RESULTADOS: Observamos que o carcinoma anal foi mais freqüente em mulheres HIV-negativas e em homens HIV-positivos e que esses ultimos eram mais jovens. As LC foram menos numerosas nos doentes HIV-positivos e as maiores contagens estavam associadas com pior evolução. Os doentes HIVpositivos com os níveis mais baixos de linfócitos T CD4+ também tiveram as piores evoluções. CONCLUSÃO: Concluímos que as LC estavam diminuídas nos doentes HIV-positivos, portadores de carcinoma anal, quando comparados aos soronegativos.

Descritores: Carcinoma anal; Células de Langerhans; Células dendríticas; Infecção pelo HPV; Infecção pelo HIV; AIDS.

\section{INTRODUÇÃO}

A incidência do carcinoma anal corresponde a $1,5 \%$ dos tumores do aparelho digestivo e entre 2 e $4 \%$ de todas as neoplasias malignas do intestino grosso. ${ }^{1,2}$ Predominava no sexo feminino na proporção de 5:1. ${ }^{3}$ Entretanto, após o surgimento da AIDS, esse tipo de tumor tem freqüência 25 a 50 vezes maior nos infectados pelo HIV, quando comparados com a população soronegativa, o que demonstra mudança importante na epidemiologia dessa neoplasia. ${ }^{2,4}$ Esse aumento vem sendo observado desde os anos 80, especialmente entre praticantes de sexo anal receptivo, ${ }^{5}$ e parece estar intimamente

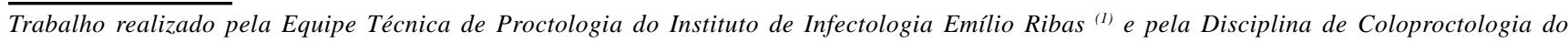
Departamento de Cirurgia da Faculdade de Ciências Médicas da Santa Casa de São Paulo ${ }^{(2)}$ - São Paulo - Brasil.

$\overline{\text { Recebido em 31/03/2006 }}$

Aceito para publicação em 01/08/2006 
relacionado com a infecção pelo Papilomavirus humano (HPV). ${ }^{6,7}$ Além disso, acredita-se que o aumento do tempo de expectativa de vida desses doentes, proporcionado pelo atual esquema de drogas antirretrovirais, possa predispor o aparecimento de maior número de tumores. ${ }^{8,9}$

Avaliando a literatura, observamos a existência de alguns fatores de risco para o aparecimento do câncer. São eles, a imunodepressão provocada pelo HIV, a associação com infecção pelo HPV, a presença dos linfócitos T CD4+ abaixo de 100/ $\mathrm{mm}^{3}$, a carga viral HIV elevada, que sugere tratamento ineficaz ou ausente e denota imunodepressão iminente, e a presença de displasias. ${ }^{10-12}$ Além desses, outros também podem estar presentes, tais como trauma, inflamação local e tabagismo. ${ }^{2}$

A importância da depressão imunológica e da infecção pelo HIV se mostra quando observamos que o tumor, antes mais freqüente em mulheres acima da sexta década da vida, ${ }^{3,13}$ começa a incidir em homens, na terceira e quarta décadas. ${ }^{14}$ Como a frequiência do câncer anal é baixa na população soronegativa e vem aumentando em doentes com AIDS, talvez o HIV seja o co-fator que o HPV necessite para induzir à displasia que poderá evoluir para carcinoma. ${ }^{4}$

A prevalência das lesões provocadas pelo HPV entre doentes HIV-positivos aumenta enquanto a contagem dos linfócitos T CD4+ diminui. ${ }^{15}$ Entretanto, a razão da transformação tumoral dessas lesões permanece incerta. Como a infecção pelo HPV e a imunodepressão elevam o risco para desenvolvimento do carcinoma anal, podemos sugerir dois passos envolvendo essa situação. O primeiro é caracterizado pelo HPV, em sua forma latente, remanescente na mucosa anal, mesmo após a erradicação dos condilomas. O segundo aspecto devese às alterações encontradas nas células dendríticas quando os condilomas reincidem. ${ }^{16}$

As células de Langerhans (LC) são células dendríticas derivadas da medula óssea que representam as principais apresentadoras de antígeno da pele (APC). Elas detectam antígenos na epiderme, migram para os linfonodos que drenam a região e os apresenta aos linfócitos T, conferindo, desta forma, a resposta imune cutânea. ${ }^{17}$ Para tanto, precisam ser ativadas, o que depende do interferon (IFN-gama), do fator de necrose tumoral (TNF-alfa) produzidos pelos linfócitos natural killer (NK) e de outros possíveis fatores adicionais. ${ }^{18}$ Todavia, as interações entre LC e NK podem se alterar em situações nas quais a imunodeficiência requer ativação imediata dessas duas células. ${ }^{19}$ As LC ativadas são estáveis, resistentes aos fatores supressores relacionados ao tumor e mostram capacidade aumentada de induzir resposta imune. ${ }^{20}$

LC também têm função nos mecanismos de defesa contra neo-antígenos nos tumores de pele. A população destas células reduz com a idade, com alguns agentes farmacológicos, incluindo corticosteróides, ciclosporina e retinóides, ${ }^{17}$ com a radiação ultravioleta, e a maioria das drogas imunossupressoras diminui o número e a função dessas células, predispondo ao aparecimento do câncer. ${ }^{21}$ Com o estabelecimento da AIDS, há aumento das LC imaturas, ${ }^{22}$ e a infecção pelo HIV estimula a atividade do HPV pela redução das LC ativadas no tecido. ${ }^{23}$ Entretanto, maior infiltração de LC foi observada em carcinomas pulmonares de infectados pelo HPV do que naqueles não contaminados por esse vírus, embora o posterior crescimento do número dessas células no tecido pulmonar esteja associado com melhor prognóstico. ${ }^{24}$ Especificamente nas lesões da cérvix uterina provocadas pelo HPV, sua diminuição parece estar ligada ao grau de atipia. ${ }^{12}$ Além disso, a inibição da sua função migratória pelos fatores derivados do tumor parece incapacitá-las a promover a imunidade protetora antitumoral. ${ }^{25} \mathrm{~A}$ infecção pelo HPV não pode explicar isoladamente a carcinogênese. De fato, o HIV determina imunodepressão local, causando resposta imune deficiente à infecção viral, o que pode explicar o aumento das taxas de displasia e câncer na área perianal. ${ }^{26}$

A função dessas células infiltrando os carcinomas anais e atuando na resposta inflamatória ainda é pouco conhecida. Parece que seu número está aumentado, porém não ocorre ativação, provavelmente por bloqueio determinado por algum fator tumoral. Sabe-se também que a incidência desses tumores é maior em doentes imunodeprimidos, nos quais os linfócitos T CD4+ estão diminuídos. ${ }^{27} \mathrm{Com}$ objetivo de conhecer as diferenças entre os carcinomas anais em situações de imunocompetênciae imunodepressão, comparamos as contagens de LC no tecido tumoral de doentes com e sem AIDS.

\section{MÉTODO}

Utilizamos os blocos de parafina contendo carcinomas anais de 24 doentes, sendo 14 portadores do HIV e 10 outros não infectados por esse vírus. Os doentes HIV-positivos eram 12 homens e duas mulheres com média etária de 41,1 anos (limites entre 29 e 55 anos) e os soronegativos eram 8 mulheres e dois homens com média de idade de 57 anos (limites entre 37 
e 82 anos). O tratamento realizado consistiu de radio e quimioterapia, sempre que as condições clínicas permitiram, seguidas de operações de resgate. $\mathrm{O}$ esquema terapêutico foi semelhante nos dois grupos.

As lâminas foram revistas para comprovação diagnóstica e os blocos de parafina dos casos confirmados sofreram cortes com micrótomo, e posteriormente foram fixados em lâminas e submetidos à reação imunohistoquímica com anticorpo anti-CD68. Após, identificamos e contamos, por método da histometria, as células de Langerhans, em 10 áreas em três campos diferentes de cada lâmina. Anotamos as médias matemáticas para cada um, que comparamos com amostras conhecidas de indivíduos sem HIV ou doença infecciosa anorretal. Utilizamos números proporcionais a esses controles.

Posteriormente, avaliamos os prontuários dos 24 doentes para verificar a evolução da doença e sua relação com o número das células estudadas.

Avaliamos os dados encontrados com o método estatístico de Kruskall-Wallis comíndice de tolerância de 5\%.

\section{RESULTADOS}

A análise estatística mostrou que o carcinoma anal foi mais freqüente nos homens HIV-po- sitivos e em mulheres HIV-negativas $(p=0,003)$ e que o grupo dos soropositivos foi o mais jovem $(p=0,002)$.

Os testes imunohistoquímicos revelaram que as médias das LC variaram de zero a 59 por campo entre os doentes HIV-positivos e de 11 a 39 por campo para os HIV-negativos. As médias foram maiores no grupo dos soronegativos, com significância estatística $(p=0,032)$ Nesse grupo de pacientes, o número correspondeu a $50 \%$ do encontrado nas amostras-padrão. Já, em metade dos portadores do HIV, essas células eram raras ou ausentes e, nos que as possuíam, as contagens mostraram-se entre 25 e $50 \%$ dos valores normais.(Tabela 1).

A análise estatística mostrou evoluções semelhantes em ambos os grupos $(p=0,697)$. Os doentes HIV-positivos que apresentaram os piores resultados tinham contagens séricas de linfócitos T CD4+ entre 4 e $21 / \mathrm{mm}^{3}$, embora o número das LC tenha sido estimado entre 25 e $75 \%$, superiores àqueles com boa evolução.(Tabela 2). Também, entre os soronegativos, a frequiência dessas células não diferiu conforme a evolução. (Tabela $3)$.

Tabela 1 - Distribuição da porcentagem das células de Langerhans conforme a sorologia para o HIV.

\begin{tabular}{lcc}
\hline \% de células de Langerhans & HIV-negativos & HIV-positivos \\
\hline ausentes ou raras & 00 & 07 \\
até $25 \%$ & 04 & 03 \\
$26-50 \%$ & 05 & 03 \\
$51-75 \%$ & 01 & 01 \\
TOTAL & 10 & 14 \\
\hline
\end{tabular}

Teste de Kuskall-Wallis: $p=0,032$ (significante).

Tabela 2 - Distribuição da porcentagem das células de Langerhans em doentes HIV-positivos conforme a evolução da doença.

\begin{tabular}{lcc}
\hline \% de células de Langerhans & Boa evolução & Má evolução \\
\hline ausentes ou raras & 06 & 01 \\
até $25 \%$ & 02 & 01 \\
$26-50 \%$ & 01 & 02 \\
$51-75 \%$ & 00 & 01 \\
TOTAL & 09 & 05 \\
\hline
\end{tabular}

Teste de Kruskall-Wallis: $p=0,052$ (não significante). 
Tabela 3 - Distribuição da porcentagem das células de Langerhans em doentes HIV-negativos conforme a evolução da doença.

\begin{tabular}{lcc}
\hline \% de células de Langerhans & Boa evolução & Má evolução \\
\hline até $25 \%$ & 03 & 01 \\
$26-50 \%$ & 03 & 02 \\
$51-75 \%$ & 00 & 01 \\
TOTAL & 06 & 04 \\
\hline
\end{tabular}

Teste de Kruskall-Wallis: $\quad p=0,289$ (não significante).

\section{DISCUSSÃO}

Nossa casuística mostrou a diferença entre sexo e idade relatada na literatura entre portadores de carcinoma anal. ${ }^{3,4,13,14}$ Entre os soronegativos, a incidência foi de quatro mulheres para um homem e, para os soropositivos para o HIV, foi seis vezes mais freqüente no sexo masculino. Já quanto à idade, nos HIV-positivos a faixa etária mais acometida esteve entre a terceira e quinta décadas e entre os HIV-negativos, nas quinta e sétima décadas.

Segundo a literatura, o número das LC na pele perianal está reduzido pela metade nos imunodeprimidos pelo HIV, ${ }^{12,23}$ favorecendo a evolução da infecção pelo HPV. ${ }^{23}$ Sabe-se, também, que o aparecimento de lesões pelo HPV é decorrente da diminuição da imunidade. ${ }^{24}$ Desta forma, podemos concluir que a presença do carcinoma anal está relacionada à imunodepressão e que a redução das LC tissulares é esperada, ${ }^{16}$ fato confirmado pelo nosso estudo. Porém, não sabemos se essa ocorrência determina ou apenas acompanha esse tipo de tumor.

Em nosso estudo, o número de LC estava reduzido nos doentes HIV-positivos quando comparados aos soronegativos. É provável que a redução da resposta imunológica seja responsável pelo menor número de LC nesse grupo de doentes. Todavia, observamos as piores evoluções em doentes HIV-positivos com as maiores contagens de LC. Acreditamos que fatores tumorais impeçam sua ativação e migração. De fato, a produção de TGF-beta-1 por tumores de pele é suficiente para imobilização das LC, impedindo sua migração para os linfonodos, reduzindo o número de células $\mathrm{T}$ que infiltrariam o tumor, evitando sua regressão. ${ }^{27}$
Nossa casuística revelou que os doentes HIV-positivos com pior evolução tinham as menores contagens séricas de linfócitos T CD4+. Revisando a literatura, observamos que a presença dessas células abaixo de $100 / \mathrm{mm}^{3}$ e a carga viral HIV elevada, que sugerem tratamento ineficaz ou ausente e denotam imunodepressão, são fatores de risco para o aparecimento do câncer. ${ }^{10-12} \mathrm{E}$, na presença deste, o prognóstico será pior nos doentes imunodeprimidos nos quais há aumento da incidência de metástases linfonodais e de recidivas, e diminuição do tempo de sobrevivência ${ }^{10,28}$ e da resposta à radio e quimioterapia. ${ }^{12}$

Análise multivariada publicada notou que o HIV foi o único fator de risco para a diminuição das LC e que a carga viral do HIV, e não as contagens séricas de linfócitos T CD4+, foi o fator preditivo de risco para a redução dessas células. ${ }^{16}$ Os mesmos autores referiram que o HPV aumenta o número de LC na mucosa anal em indivíduos HIV-negativos e que o HIV altera as células dendríticas, conduzindo ao aumento do risco para câncer anal. ${ }^{16}$

Ainda são poucos os trabalhos que avaliam a importância das contagens de LC no carcinoma anal. Acreditamos que serão necessários mais estudos para averiguar se o número dessas células pode ter valor no prognóstico dos portadores desse tipo de câncer.

\section{CONCLUSÃO}

Os resultados obtidos no presente estudo permitem concluir que as LC estavam diminuídas nos doentes imunodeprimidos portadores de carcinoma anal, quando comparados aos imunocompetentes. 
Comparação das Contagens das Células de Langerhans de Tecidos Contendo Carcinoma Anal em Doentes com e sem Infecção pelo HIV Sidney Roberto Nadal e Cols.

\begin{abstract}
Langerhans cells (LC) are bone marrow derived dendritic cells that represent the major antigen-presenting cells (APC) in the skin, thus representing an integral part of the cutaneous immune response. Immunossupression decreases their number, including HIV infection, and skin tumors products are sufficient to immobilize LC within the tumor, preventing their migration to lymph nodes. This reduces the number of $T$ cells that infiltrate the tumor, preventing regression. OBJETIVE: Our proposal was to know what are the differences among LC counts comparing HIV-positive and -negative patients with anal carcinoma. METHOD: We evaluated 24 patients, 14 with HIV and 10 HIV-negative. Treatment for carcinoma was similar in both groups. Paraffin blocks containing biopsies were cut and stained with antibody anti-CD68. LC were counted in a histometrical way and number were compared to previous known specimens of HIV-negative patients without infectious anorectal diseases. We also studied cancer evolution and T CD4+ lymphocytes blood counts of HIV-positive patients. RESULTS: Statistics showed that anal carcinomas were more frequent in females HIV-negative and in seropositive males. HIV-positive patients were younger than seronegative ones. LC were decreased in seropositive patients and the most numerous counts were associated to worse prognosis. HIV-positive patients who had the most decreased T CD4+ counts had the worst prognosis, too. CONCLUSION: We conclude that LC were decreased in HIV-positive patients with anal carcinoma rather than in seronegative.
\end{abstract}

Key words: Anal carcinoma anal; Langerhans cells; Dendritic cells; HPV infection; HIV infection; AIDS.

\section{REFERÊNCIAS}

1. Stearns MW Jr, Urmacher C, Sternberg SS, Woodruff J, Attiyeh F. Cancer of the anal canal. Curr Probl Cancer 1980;4:144.

2. Ryan DP, Campton CC, Mayer RJ. Carcinoma of the anal canal. N Engl J Med 2000;342:798-800.

3. Moscicki AB, Hills NK, Shiboski S, Darragh TM, Jay N, Powell K, et al. Risk factors for abnormal anal cytology in young heterosexual women. Cancer Epidemiol Biomarkers Prev 1999; 8:173-8.

4. Modesto VL, Gottesman L. Doenças sexualmente transmitidas e manifestações anais da AIDS. Clin Cir Am Norte 1994;74:1501-34.

5. Lytwyn A, Salit IE, Raboud J, Chapman W, Darragh T, Winkler $\mathrm{B}$, et al. Interobserver agreement in the interpretation of anal intraepithelial neoplasia. Cancer 2005;103:1447-56.

6. Frisch M, Fenger C, Van Den Brule AJ, Sorensen P, Meijer CJ, Walboomers JM, et al. Variants of squamous cell carcinoma of the anal canal and perianal skin and their relation to human papillomaviruses. Cancer Res 1999;59:753-7.

7. Gervaz P, Allal AS, Villiger P, Buhler L, Morel P. Squamous cell carcinoma of the anus: another sexually transmitted disease. Swiss Med Wkly 2003;133:353-9.

8. Berretta M, Cinelli R, Martellotta F, Spina M, Vaccher E, Tirelli U. Therapeutic approaches to AIDS-related malignancies. Oncogene. 2003;22: 6646-59.

9. Berry JM, Palefsky JM, Welton ML. Anal cancer and its precursors in HIV-positive patients: perspectives and management. Surg Oncol Clin N Am. 2004;13:355-73.

10. Kim JH, Sarani B, Orkin BA, Young HA, White J, Tannebaum I, et al. HIV-positive patients with anal carcinoma have poorer treatment tolerance and outcome than HIV-negative patients. Dis Colon Rectum. 2001;44:1496-502.

11. Place RJ, Huber PJ, Simmang CL. Anorectal lymphoma and AIDS: an outcome analysis. J Surg Oncol 2000;73:1-4.
12. Sobhani I, Vuagnat A, Walker F, Vissuzaine C, Mirin B, Hervatin F, et. Prevalence of high-grade dysplasia and cancer in the anal canal in human papillomavirus-infected individuals. Gastroenterology 2001;120:857-66.

13. Klas JV, Rothenberger DA, Wong WD, Madoff RD. Malignant tumors of the canal anal: the spectrum of diease, treatment and outcomes. Cancer 1999;85:1686-93

14. Friedman HB, SaahAJ, Sherman ME, Busseniers AE, Blackwelder WC, Kaslow RA, et al. Human papillomaviruses, anal squamous intraepithelial lesions, and human immunodeficiency virus in a cohort of gay men. J Infect Dis 1998;178:45-52.

15. Breese PL, Judson FN, Penley KA, Douglas Jr JM. Anal human papillomavirus infection among homosexual and bisexual men: prevalence of type-specific infection and association with human immunodeficiency virus. Sex Transm Dis 1995;22:7-14.

16. Sobhani I, Walker F, Aparicio T, Abramowitz L, Henin D, Cremieux AC, et al. Effect of anal epidermoid cancer-related viruses on the dendritic (Langerhans) cells of the human anal mucosa. Clin Cancer Res 2002;8:2862

17. Suzuki H, Wang B, Shivji GM, Toto P, Amerio P, Tomai MA, et al. Imiquimod, a topical immune response modifier, induces migration of Langerhans cells. J Invest Dermatol 2000;114:135-41.

18. Cumberbatch M, Dearman RJ, Groves RW, Antonopoulos C, Kimber I. Differential regulation of epidermal langerhans cell migration by interleukins (IL)-1alpha and IL-1beta during irritant- and allergen-induced cutaneous immune responses. Toxicol Appl Pharmacol 2002 15;182:126-35.

19. Andrews DM, Andoniou CE, Scalzo AA, Van Dommelen SL, Wallace ME, Smyth MJ, et al. Cross-talk between dendritic cells and natural killer cells in viral infection. Mol Immunol 2005;42:547-55.

20. Kalinski P, Giermasz A, Nakamura Y, Basse P, Storkus WJ, Kirkwood JM, et al. Helper role of NK cells during the induction of anticancer responses by dendritic cells. Mol Immunol. 2005;42:535-9. 
21. Bergfelt L. Langerhans cells, immunomodulation and skin lesions. A quantitative, morphological and clinical study. Acta Derm Venereol Suppl (Stockh) 1993;180:1-37.

22. Goncalves MA, Soares EG, Fernandes AP, Fonseca BA, Bettini JS, Simoes RT, et al. Langerhans' cell count and HLA class II profile in cervical intraepithelial neoplasia in the presence or absence of HIV infection. Eur J Obstet Gynecol Reprod Biol 2004;114:221-7.

23. Sobhani I, Walker F, Roudot-Thoraval F, Abramowitz L, Johanet H, Henin D, et al. Anal carcinoma: incidence and effect of cumulative infections. AIDS 2004;18:1561-9.

24. Miyagi J, Kinjo T, Tsuhako K, Higa M, Iwamasa T, Kamada $\mathrm{Y}$, et al. Extremely high Langerhans cell infiltration contributes to the favourable prognosis of HPV-infected squamous cell carcinoma and adenocarcinoma of the lung. Histopathology 2001;38:355-67.

25. Lucas AD, Halliday GM. Progressor but not regressor skin tumours inhibit Langerhans' cell migration from epidermis to local lymph nodes. Immunology 1999;97:130-7.
26. Arany I, Evans T, Tyring SK. Tissue specific HPV expression and downregulation of local immune responses in condylomas from HIV seropositive individuals. Sex Transm Infect 1998;74:349-53.

27. Weber F, Byrne SN, Le S, Brown DA, Breit SN, Scolyer RA, et al. Transforming growth factor-beta(1) immobilises dendritic cells within skin tumours and facilitates tumour escape from the immune system. Cancer Immunol Immunother 2005;54:898-906.

28. Vatra B, Sobhani I, Aparicio T, Girard PM, Puy Montbrun TD, Housset M, et al. Anal canal squamous-cell carcinomas in HIV positive patients: clinical features, treatments and prognosis. Gastroenterol Clin Biol 2002; 26:150-6.

Endereço para correspondência: SIDNEY ROBERTO NADAL

Rua Dr. Virgilio de Carvalho Pinto, 381 apto 23

05.415-030 - São Paulo (SP)

Fone/FAX: (0xx11) 32238099 e 3337-4282

E-mail:srnadal@terra.com.br 